\title{
Training nurses to reduce child mortality
}

\author{
Author: \\ Neil H. McKerrow \\ Affiliation: \\ ${ }^{1}$ South Africa and \\ Department of Paediatrics \& \\ Child Health, Nelson R \\ Mandela School of Medicine \\ Faculty of Health Sciences, \\ University of KwaZulu-Natal, \\ South Africa \\ Email: \\ neil.mckerrow@kznhealth. \\ gov.za \\ How to cite this article: \\ McKerrow, N.H., 2014, \\ 'Training nurses to reduce \\ child mortality', Curationis \\ 37(2), Art. \#1475, 2 pages. \\ http://dx.doi.org/10.4102/ \\ curationis.v37i2.1475

\section{Copyright:} \\ (C) 2014. The Authors. \\ Licensee: AOSIS \\ OpenJournals. This \\ work is licensed under \\ the Creative Commons \\ Attribution License.
}

Read online:

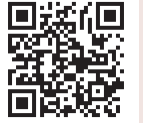

Scan this QR code with your smart phone or mobile device to read online.
After a shaky start, South Africa is finally making progress towards achieving the fourth of the eight Millennium Development Goals (MDGs), namely to reduce under-five mortality by twothirds between 1990 and 2015 (UNDP 2003). However, whilst there has been a sustained decline in the country's under-five mortality rate (U5MR), this has only occurred since 2007 and the MDG target of 20 is unlikely to be realised within the final 500 days.

The latest vital registration data for 2011 (Statistics South Africa 2014) suggests a national U5MR of 38.5 per 1000 live births, which is down from both the estimated 1990 baseline of 62 and the 2007 figure of 62.1 (NDoH 2011). Almost a third of these deaths occur during the first month of life, producing a neonatal mortality rate (NNMR) of 11.2, and three-quarters occur within a year of birth, resulting in an infant mortality rate (IMR) of 28.4. Since 2007 most of the gains in underfive survival have occurred in the postneonatal period, with the NNMR remaining in a narrow range between 12 and 14 deaths per 1000 live births. These national figures conceal a marked interprovincial inequity, with a threefold variation between the Western Cape (with the lowest U5MR at 24.1) and the Free State, where the U5MR is 71.2.

Prematurity, birth asphyxia and sepsis account for most deaths during the neonatal period and, collectively, neonatal illnesses are the most common cause of death in infancy and early childhood. In the postneonatal period, gastroenteritis and acute respiratory illnesses come to the fore, and from one year of age non-natural deaths and tuberculosis play an increasing role in child mortality (Statistics South Africa 2014). Two conditions underlie many of these deaths: $34 \%$ of children dying in public sector hospitals are severely malnourished, whilst just over half are infected with or exposed to the human immunodeficiency virus (HIV) (eds. Stephen et al. 2011). Almost half (45.5\%) of all deaths amongst children below five years of age occur outside the health services (Statistics South Africa 2014), and of those deaths in the public health sector more than a quarter occur within the first 24 hours of admission (eds. Stephen et al. 2011).

Audits of childhood deaths in public hospitals suggest that approximately a quarter of these deaths are avoidable (Stephen et al. 2011). Avoidable factors, which are amenable to the intervention of nursing professionals, occur at both the household and primary health care levels. At the household level, these include poor food security leading to malnutrition, failure of the caregiver to appreciate the severity of the child's illness, and the subsequent delay in seeking health care. In the primary health care clinics the most frequent avoidable factors are poor growth monitoring, a delay in the referral of malnourished children to higher levels of care and failure to apply the integrated management of childhood illnesses (IMCI) case management algorithms, especially those applicable to HIV infection (NDoH 2011).

Various general and specific initiatives - including the reengineering of primary health care services, the launch of a Strategic Plan for Maternal, Newborn, Child and Women's Health and Nutrition (MNCWH \& N) in South Africa, the adoption of the Campaign for the Accelerated Reduction of Maternal Mortality in Africa (CARMMA), and the introduction of dashboards and mortality targets for health facilities - have been adopted by the National Department of Health in order to strengthen health services, as well as improve the standard of maternal and child wellbeing in the country. Central to the success of all these initiatives is the creation of an appropriately skilled workforce. This was recognised by the Ministerial Committee on Morbidity and Mortality in Children Under 5 Years (CoMMiC) in its first triennial report (NDoH 2011). The report emphasised the need to strengthen and focus pre-service, post-graduate and in-service training in child health and paediatrics on the essentials required to care for children in the South African health system.

The committee believes that the interpretation and implementation of the curriculum for nurses, related to paediatrics and child health, is site-specific, lacks uniformity and is often incomplete. It is therefore essential that both the curriculum content and the training platform are reviewed 
and strengthened in order to establish a nursing workforce that is able to meet the needs of children in this country.

The curriculum content for basic nurse training needs to emphasise routine neonatal care, growth and nutrition (including growth monitoring and promotion), feeding and malnutrition, IMCI and key community child health programmes, the basic care of common childhood illnesses and trauma, resuscitation and emergency care, as well as clinical governance and quality improvement. These goals are best achieved by ensuring that all nurses in training are exposed to those programmes already being implemented in the public health service, across a training platform that includes community, district and regional levels of service delivery.

Post-basic nurse education needs to support the progressive realisation of a health service in which, firstly, it is ensured that the operational manager (OM) of every nursery and children's ward has a specialist qualification; thereafter, every shift leader should be specialist-trained. Step three aims to ensure that $20 \%$ of professional nurses in each nursery and ward are specialists; thereafter, at least half $(50 \%)$ of all nurses in these wards should be specialists.

Advanced midwifery is an appropriate qualification for a district level nursery, provided the neonatal component, both theoretical and experiential, of the training is strengthened. Neonatal nurseries at a higher level of care require a nurse with more in-depth training in neonatal care. This requires the recognition of this cadre and the reintroduction of such training. The speciality for a children's ward, at all levels of care, should be in paediatrics or Child Health Nursing. Finally, in the paediatric intensive care unit a nurse with a suitable qualification in paediatric critical care nursing is required, rather than one with an adult qualification that includes a paediatric module.

Given the high NNMR, it is crucial that all paediatric courses - post-basic paediatrics, Child Health Nursing and paediatric intensive care nursing - include modules on newborn care and that neonatal training includes greater exposure to modern modalities of care.

Nurses are the backbone of the South African public health service and if the current decline in under-five mortality is to be maintained, it is critical to develop and deploy a cadre of suitably skilled nurses across all level of this service. This requires the review of current training.

\section{References}

National Department of Health (NDoH), 2011, First report of the Committee on Morbidity and Mortality in Children Under 5 Years (CoMMiC): 2008-2010, NDoH, Pretoria.

Statistics South Africa, 2014, Mortality and causes of death in South Africa, 2011 Findings from death notification, Statistics South Africa, Pretoria.

Stephen C.R., Bamford L.J., Patrick M.E. \& Wittenberg D.F. (eds.), 2011, Saving children 2009: Five years of data. A sixth survey of child healthcare in South Africa, Tshepesa Press, Pretoria.

United Nations Development Programme (UNDP), 2003, Human Development Report 2003. Millennium Development Goals: A compact among nations to end human poverty, UNDP, New York, viewed 20 August 2014, from http://hrd.undp.org/ content/human-development-report-2003 